\title{
Quantitative Evaluation of Radiation Dose Rates for Depleted Uranium in PRIDE Facility
}

\author{
II Je Cho ${ }^{1,2, *}$, Jee Hyung Sim², Yong Soo Kim² \\ ${ }^{1}$ Division of Nuclear Fuel Process Development, Korea Atomic Energy Research Institute, Daejeon, Korea; ${ }^{2}$ Department of Nuclear Engineering, Hanyang \\ University, Seoul, Korea
}

\section{Technical Paper}

Received July 17, 2015

Revision October 3, 2016

Accepted November 14, 2016

Corresponding author: II Je Cho

Korea Atomic Energy Research Institute (KAERI), 989-111 Daedeok-daero,

Yuseong-gu, Daejeon 34057, Korea

Tel: +82-42-868-2485,

Fax: +82-42-868-2864,

E-mail: hyilje@kaeri.re.kr

This is an Open-Access article distributed under the terms of the Creative Commons Attribution NonCommercial License (http://creativecommons.org/ licenses/by-nc/4.0) which permits unrestricted noncommercial use, distribution, and reproduction in any medium, provided the original work is properly cited.

Copyright $\odot 2016$ The Korean Association for Radiation Protection

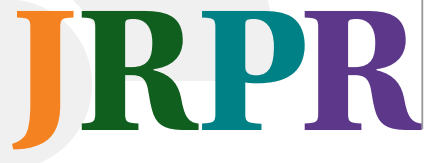

Background: Radiation dose rates in PRIDE facility is evaluated quantitatively for assessing radiation safety of workers because of large amounts of depleted uranium being handled in PRIDE facility. Even if direct radiation from depleted uranium is very low and will not expose a worker to significant amounts of external radiation.

Materials and Methods: ORIGEN-ARP code was used for calculating the neutron and gamma source term being generated from depleted uranium (DU), and the MCNP5 code was used for calculating the neutron and gamma fluxes and dose rates.

Results and Discussion: The neutron and gamma fluxes and dose rates due to DU on spherical surface of $30 \mathrm{~cm}$ radius were calculated with the variation of DU mass and density. In this calculation, an imaginary case in which DU density is zero was added to check the self-shielding effect of DU. In this case, the DU sphere was modeled as a point. In case of DU mixed with molten salt of 50-250 g, the neutron and gamma fluxes were calculated respectively. It was found that the molten salt contents in DU had little effect on the neutron and the gamma fluxes. The neutron and the gamma fluxes, under the respective conditions of 1 and $5 \mathrm{~kg}$ mass of DU, and 5 and $19.1 \mathrm{~g}^{-\mathrm{cm}^{-3}}$ density of DU, were calculated with the molten salt $(\mathrm{LiCl}+\mathrm{KCl})$ of $50 \mathrm{~g}$ fixed, and compared with the source term. As the results, similar tendency was found in neutron and gamma fluxes with the variation of DU mass and density when compared with source spectra, except their magnitudes.

Conclusion: In the case of the DU mass over $5 \mathrm{~kg}$, the dose rate was shown to be higher than the environmental dose rate. From these results, it is concluded that if a worker would do an experiment with DU having over $5 \mathrm{~kg}$ of mass, the worker should be careful in order not to be exposed to the radiation.

Keywords: PyRoprocess Integrated inactive DEmonstration facility (PRIDE), Depleted uranium (DU), Dose rates, Neutron and gamma flux

\section{Introduction}

Pyroprocess Integrated inactive DEmonstration Facility (PRIDE) is a test facility to simulate the integrate process of pyroporcessing in engineering scale to realize the pyroprocessing technology. PRIDE is a three-story building and it has a large-scale argon atmosphere cell (40.3 m length, $4.8 \mathrm{~m}$ width, $6.4 \mathrm{~m}$ height) at the second floor. PRIDE utilities systems can maintain the argon cell within the desired operations requirements concentration of oxygen and moisture $<50 \mathrm{ppm}$, respectively. PRIDE is of $50 \mathrm{~kg}$ per batch capacity. It will use depleted uranium with surrogate materials to show integrated performance and scale-up technologies of pyroprocessing. Major process equipments 
installed in the argon cell are electrolytic reducer, cathode processor, electrowinner, waste molten salt treatment apparatus. Operation and remote handling systems can do all remote handling, operation, maintenance, material and equipment transfer, monitoring and etc., inside argon cell.

Depleted uranium, DU generates too little radiation compared with spent nuclear fuel, so the influence of DU on the workers and environment may be negligible in the course of doing process tests, and transporting and storing of DU. But radiation dose rates in PRIDE facility were evaluated quantitatively for assessing radiation safety of workers because of large amounts of depleted uranium being handled in PRIDE facility. Even if direct radiation from depleted uranium is very low and will not expose a worker to significant amounts of external radiation.

The products would be stored inside a sealed basket or can to prohibit from absorbing moisture from air. The calculated radiation dose rates via mass variation of DU can be applied to expect the amounts of DU inside a sealed basket or can without measuring amounts of DU with salt by chemical analyses. So radiation can roughly guide the amount of DU in a sealed basket or can. For the quantitative evaluation on the DU characteristics, sensitivity analyses of the variations of neutron and gamma fluxes and dose rates were made at the four DU densities, 5, 10, 15, and $19.1 \mathrm{~g} \cdot \mathrm{cm}^{-3}$, and six masses, 1 , $3,5,7,10$, and $20 \mathrm{~kg}$, respectively.

\section{Materials and Methods}

In this study, the ORIGEN-ARP code [1] was used for calculating the neutron and gamma source term being generated from DU, and the MCNP5 code (Build 1.40) [2] was used for calculating the neutron and gamma fluxes and dose rates. ORIGEN-ARP is a depletion analysis sequence in SCALE which is used to perform point-depletion calculations. MCNP is a general-purpose Monte Carlo N-Particle code for radiation shielding, radiation protection and dosimetry, etc. developed by Los Alamos National Laboratory. ENDF/B-VI point-wise cross-section library was employed in this work for MCNP5 calculation.

\section{Source term}

DU composition about $0.001 w t \%{ }^{234} \mathrm{U}, 0.2 \mathrm{wt} \%{ }^{235} \mathrm{U}$ and about $99.8 \mathrm{wt} \%{ }^{238} \mathrm{U}$ is used in this calculation. Neutron and gamma energy spectra being generated from $100 \mathrm{~g}$ DU were calculated using ORIGEN-ARP with 44-energy-group structure.

To calculate the saturated gamma intensity from DU, sensitivity calculations for 6 decay periods were carried out, and the results are shown in Table 1. From the results, it is found that one year is sufficient to get saturated gamma intensity as the decay period in ORIGEN-ARP calculation. As the results of source term calculation, the neutron intensity was calculated to be $1.372 \# \cdot \sec ^{-1}$ and the gamma intensity $1.328 \times 10^{6}$ $\# \cdot \sec ^{-1}$. Neutron and gamma energy spectra are presented in Table 2 and Table 3, respectively.

\section{MCNP modeling}

The basic MCNP modeling for calculating the neutron and gamma fluxes and dose rates from DU are shown in Figure 1. In this work, DU was modeled as a sphere, and the fluxes

Table 2. Neutron Energy Spectrum of DU

\begin{tabular}{cccc}
\hline Energy [MeV] & Fraction & Energy [MeV] & Fraction \\
\hline $3.00 \times 10^{-9}$ & $5.616 \times 10^{-13}$ & $4.75 \times 10^{-6}$ & $2.448 \times 10^{-9}$ \\
$7.50 \times 10^{-9}$ & $5.282 \times 10^{-13}$ & $6.00 \times 10^{-6}$ & $2.062 \times 10^{-9}$ \\
$1.00 \times 10^{-8}$ & $2.916 \times 10^{-13}$ & $8.10 \times 10^{-6}$ & $3.964 \times 10^{-9}$ \\
$2.53 \times 10^{-8}$ & $1.992 \times 10^{-12}$ & $1.00 \times 10^{-5}$ & $4.065 \times 10^{-9}$ \\
$3.00 \times 10^{-8}$ & $6.902 \times 10^{-13}$ & $3.00 \times 10^{-5}$ & $6.290 \times 10^{-8}$ \\
$4.00 \times 10^{-8}$ & $1.584 \times 10^{-12}$ & $1.00 \times 10^{-4}$ & $3.962 \times 10^{-7}$ \\
$5.00 \times 10^{-8}$ & $1.733 \times 10^{-12}$ & $5.50 \times 10^{-4}$ & $5.641 \times 10^{-6}$ \\
$7.00 \times 10^{-8}$ & $3.871 \times 10^{-12}$ & $3.00 \times 10^{-3}$ & $7.175 \times 10^{-5}$ \\
$1.00 \times 10^{-7}$ & $6.707 \times 10^{-12}$ & $1.70 \times 10^{-2}$ & $9.689 \times 10^{-4}$ \\
$1.50 \times 10^{-7}$ & $1.323 \times 10^{-11}$ & $2.50 \times 10^{-2}$ & $8.166 \times 10^{-4}$ \\
$2.00 \times 10^{-7}$ & $1.544 \times 10^{-11}$ & $1.00 \times 10^{-1}$ & $1.276 \times 10^{-2}$ \\
$2.25 \times 10^{-7}$ & $8.457 \times 10^{-12}$ & $4.00 \times 10^{-1}$ & $9.266 \times 10^{-2}$ \\
$2.50 \times 10^{-7}$ & $8.909 \times 10^{-12}$ & $9.00 \times 10^{-1}$ & $1.990 \times 10^{-1}$ \\
$2.75 \times 10^{-7}$ & $9.347 \times 10^{-12}$ & 1.40 & $1.889 \times 10^{-1}$ \\
$3.25 \times 10^{-7}$ & $1.991 \times 10^{-11}$ & 1.85 & $1.407 \times 10^{-1}$ \\
$3.50 \times 10^{-7}$ & $1.053 \times 10^{-11}$ & 2.35 & $1.210 \times 10^{-1}$ \\
$3.75 \times 10^{-7}$ & $1.091 \times 10^{-11}$ & 2.48 & $2.426 \times 10^{-2}$ \\
$4.00 \times 10^{-7}$ & $1.126 \times 10^{-11}$ & 3.00 & $7.976 \times 10^{-2}$ \\
$6.25 \times 10^{-7}$ & $1.158 \times 10^{-10}$ & 4.80 & $1.137 \times 10^{-1}$ \\
$1.00 \times 10^{-6}$ & $2.418 \times 10^{-10}$ & 6.43 & $2.064 \times 10^{-2}$ \\
$1.77 \times 10^{-6}$ & $6.454 \times 10^{-10}$ & 8.19 & $4.016 \times 10^{-3}$ \\
$3.00 \times 10^{-6}$ & $1.351 \times 10^{-9}$ & $2.00 \times 10^{1}$ & $7.048 \times 10^{-4}$ \\
\hline & & &
\end{tabular}

Table 1. Changes in Gamma Intensity Depending on Decay Period (DU: 100 g)

\begin{tabular}{lcccccc}
\hline Decay period & $1 \mathrm{sec}$ & 1 day & 1 year & 3 year & 10 year & 30 year \\
\hline gamma intensity $\left(\# \cdot \mathrm{sec}^{-1}\right)$ & $1.527 \times 10^{5}$ & $1.959 \times 10^{5}$ & $1.328 \times 10^{6}$ & $1.327 \times 10^{6}$ & $1.327 \times 10^{6}$ & $1.327 \times 10^{6}$ \\
\hline
\end{tabular}


Table 3. Gamma Energy Spectrum of DU with Decay Period of 1 Year

\begin{tabular}{cccc}
\hline Energy [MeV] & Fraction & Energy [MeV] & Fraction \\
\hline $2.00 \times 10^{-2}$ & $4.194 \times 10^{-1}$ & 1.57 & $2.187 \times 10^{-4}$ \\
$3.00 \times 10^{-2}$ & $9.691 \times 10^{-2}$ & 1.66 & $8.629 \times 10^{-5}$ \\
$4.50 \times 10^{-2}$ & $7.475 \times 10^{-2}$ & 1.80 & $2.991 \times 10^{-4}$ \\
$6.00 \times 10^{-2}$ & $5.672 \times 10^{-2}$ & 2.00 & $3.470 \times 10^{-4}$ \\
$7.00 \times 10^{-2}$ & $6.752 \times 10^{-2}$ & 2.15 & $1.459 \times 10^{-6}$ \\
$7.50 \times 10^{-2}$ & $1.154 \times 10^{-2}$ & 2.35 & $2.803 \times 10^{-7}$ \\
$1.00 \times 10^{-1}$ & $1.003 \times 10^{-1}$ & 2.50 & $4.152 \times 10^{-9}$ \\
$1.50 \times 10^{-1}$ & $5.166 \times 10^{-2}$ & 3.00 & $1.625 \times 10^{-7}$ \\
$2.00 \times 10^{-1}$ & $4.047 \times 10^{-2}$ & 3.50 & $9.420 \times 10^{-8}$ \\
$3.00 \times 10^{-1}$ & $2.693 \times 10^{-2}$ & 4.00 & $5.461 \times 10^{-8}$ \\
$4.00 \times 10^{-1}$ & $1.879 \times 10^{-2}$ & 4.50 & $3.166 \times 10^{-8}$ \\
$4.50 \times 10^{-1}$ & $5.529 \times 10^{-3}$ & 5.00 & $1.835 \times 10^{-8}$ \\
$5.10 \times 10^{-1}$ & $5.439 \times 10^{-3}$ & 5.50 & $1.064 \times 10^{-8}$ \\
$5.12 \times 10^{-1}$ & $1.495 \times 10^{-5}$ & 6.00 & $6.169 \times 10^{-9}$ \\
$6.00 \times 10^{-1}$ & $2.562 \times 10^{-3}$ & 6.50 & $3.577 \times 10^{-9}$ \\
$7.00 \times 10^{-1}$ & $3.672 \times 10^{-3}$ & 7.00 & $2.074 \times 10^{-9}$ \\
$8.00 \times 10^{-1}$ & $5.496 \times 10^{-3}$ & 7.50 & $1.203 \times 10^{-9}$ \\
1.00 & $6.968 \times 10^{-3}$ & 8.00 & $6.972 \times 10^{-10}$ \\
1.20 & $3.649 \times 10^{-3}$ & $1.00 \times 10^{1}$ & $8.238 \times 10^{-10}$ \\
1.33 & $3.739 \times 10^{-4}$ & $1.20 \times 10^{1}$ & $4.257 \times 10^{-11}$ \\
1.44 & $2.535 \times 10^{-4}$ & $1.40 \times 10^{1}$ & 0 \\
1.50 & $7.027 \times 10^{-5}$ & $2.00 \times 10^{1}$ & 0 \\
\hline
\end{tabular}

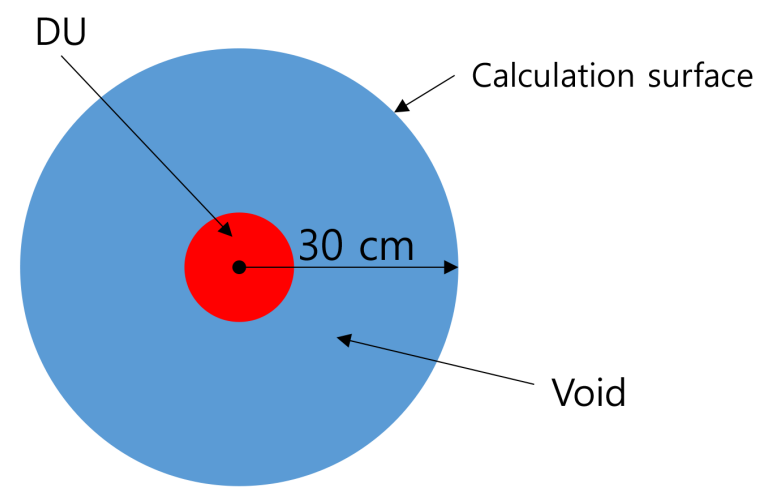

Fig. 1. Depleted uranium in MCNP modeling and its calculated location.

and dose rates were calculated on the surface of the sphere with $30 \mathrm{~cm}$ radius.

In the model, DU size would be changed according to its density, mass, and molten salt content to be mixed into DU. Four DU densities, 5, 10, 15, and $19.1 \mathrm{~g} \cdot \mathrm{cm}^{-3}$, were employed in order to investigate the changes of neutron and gamma fluxes and dose rates by density variation. Six masses, 1, 3, 5, 7,10 , and $20 \mathrm{~kg}$, by mass variation, and five masses of molten salt, 50, 100, 150, 200, and $250 \mathrm{~g}$, by molten salt mass variation. In the calculation for mixed DU with molten salt, DU mass of $5 \mathrm{~kg}$ and the molten salt density of $1.62 \mathrm{~g} \cdot \mathrm{cm}^{-3}$ were
Table 4. Radius of Calculation Sphere by Mass-Density of DU (Unit: $\mathrm{cm})$

\begin{tabular}{lccccccc}
\hline $\begin{array}{l}\text { Mensity } \\
\left(\mathrm{g} \cdot \mathrm{cm}^{-3}\right)\end{array}$ & 1 & 3 & 5 & 7 & 10 & 20 \\
\hline 5 & 3.62783 & 5.23224 & 6.20350 & 6.93979 & 7.81593 & 9.84745 \\
10 & 2.87941 & 4.15283 & 4.92373 & 5.50812 & 6.20350 & 7.81593 \\
15 & 2.51540 & 3.62783 & 4.30127 & 4.81178 & 5.41926 & 6.82784 \\
19.1 & 2.32074 & 3.34708 & 3.96841 & 4.43941 & 4.99988 & 6.29945 \\
\hline
\end{tabular}

Table 5. Radius of Calculation Sphere by Molten Salt Mass

\begin{tabular}{|c|c|c|c|c|c|c|c|}
\hline \multicolumn{3}{|c|}{ Molten salt } & \multicolumn{3}{|c|}{ Depleted uranium } & \multirow{4}{*}{$\begin{array}{c}\text { Mixture } \\
\text { volume } \\
\left(\mathrm{cm}^{3}\right)\end{array}$} & \multirow{4}{*}{$\begin{array}{l}\text { Radius of } \\
\text { sphere }\end{array}$} \\
\hline $\begin{array}{l}\text { Density } \\
\left(\mathrm{g} \cdot \mathrm{cm}^{-3}\right)\end{array}$ & $\begin{array}{l}\text { Mass } \\
\text { (g) }\end{array}$ & $\begin{array}{l}\text { Volume } \\
\left(\mathrm{cm}^{3}\right)\end{array}$ & $\begin{array}{l}\text { Density } \\
\left(\mathrm{g} \cdot \mathrm{cm}^{-3}\right)\end{array}$ & $\begin{array}{l}\text { Mass } \\
\text { (g) }\end{array}$ & $\begin{array}{l}\text { Volume } \\
\left(\mathrm{cm}^{3}\right)\end{array}$ & & \\
\hline \multirow[t]{5}{*}{1.62} & 50 & 30 & 5 & 5,000 & 1,000 & & \\
\hline & 100 & 60 & & & & & \\
\hline & 150 & 90 & & & & 1,090 & 6.38964 \\
\hline & 200 & 120 & & & & 1,120 & 6.44934 \\
\hline & 250 & 150 & & & & 1,150 & 6.50795 \\
\hline
\end{tabular}

fixed in order to find the only effect due to the variation of molten salt density. The radii of the calculation spheres with the variation of density and mass of DU were presented in Table 4 and the radii with the variation of molten salt mass in Table 5.

In addition, the effect of stainless steel container which is used to transport DU was analyzed on neutron and gamma fluxes. The stainless steel container of $3 \mathrm{~mm}$ thickness was assumed to fully surround DU sphere in this MCNP modeling. In this calculation, the molten salt content was fixed as $50 \mathrm{~g}$ against the DU masses of 1 and $5 \mathrm{~kg}$, and the densities of 5 and $19.1 \mathrm{~g} \cdot \mathrm{cm}^{-3}$. F2 tally (flux averaged over the surface) was used in all the calculations including stainless steel container.

\section{Results and Discussions}

\section{Flux and dose rate with the variation of DU density}

The neutron and gamma fluxes and dose rates due to DU on spherical surface of $30 \mathrm{~cm}$ radius were calculated with the variation of DU mass and density. In this calculation, an imaginary case in which DU density is zero was added to check the self-shielding effect of DU. In this case, the DU sphere was modeled as a point.

The neutron flux and dose rate were shown in Figures 2 and 3 , respectively, and the gamma flux and dose rate were Figures 4 and 5, respectively. As seen in Figures 2 to 5, the gamma fluxes were found to be slightly reduced as DU den- 


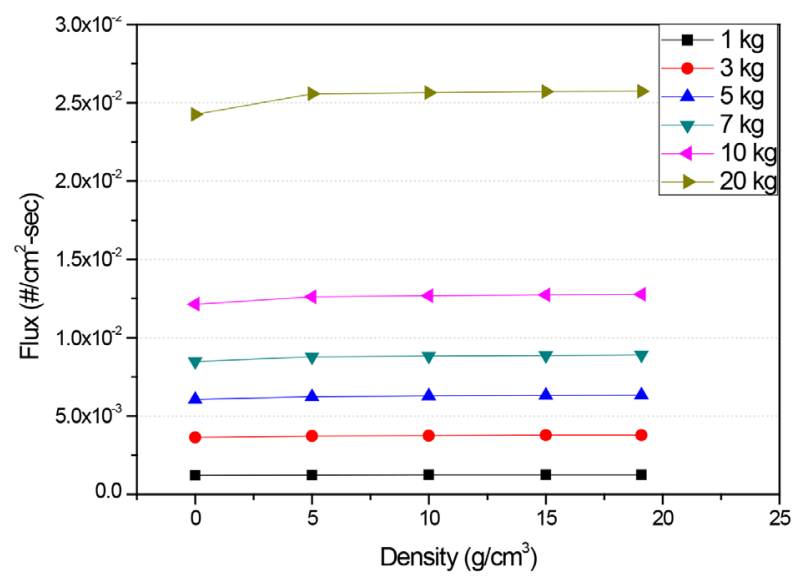

Fig. 2. Neutron flux with the variation of DU density.

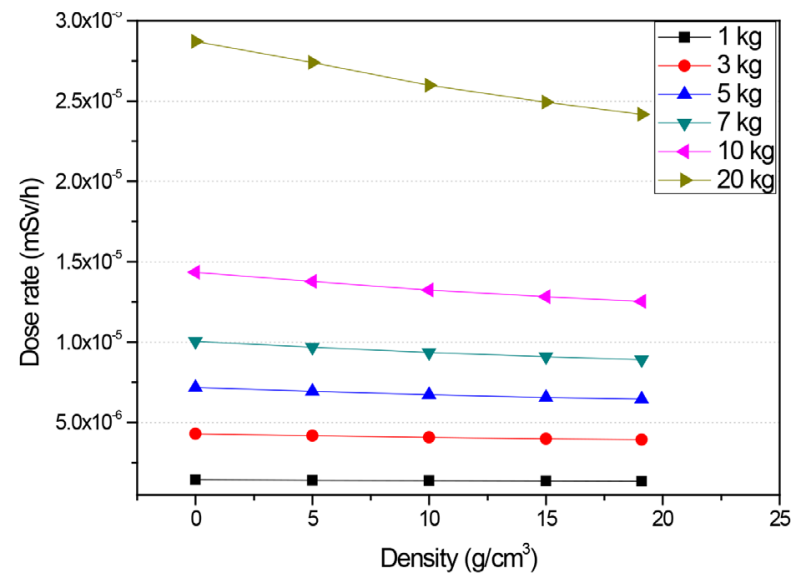

Fig. 3. Neutron dose rate with the variation of DU density.

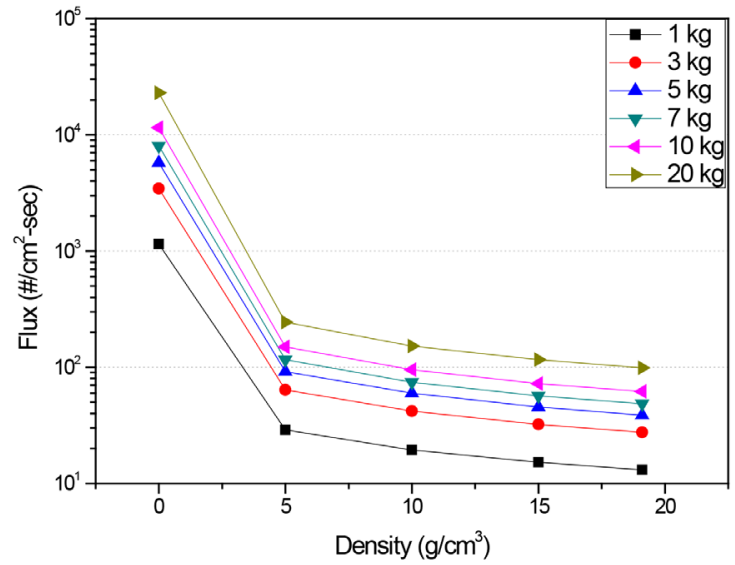

Fig. 4. Gamma flux with the variation of DU density.

sity changes, on the other hand, the neutron fluxes nearly constant. It was also found that the substantial differences between gamma fluxes at zero density and other densities were occurred due to the self-shielding effect of DU.

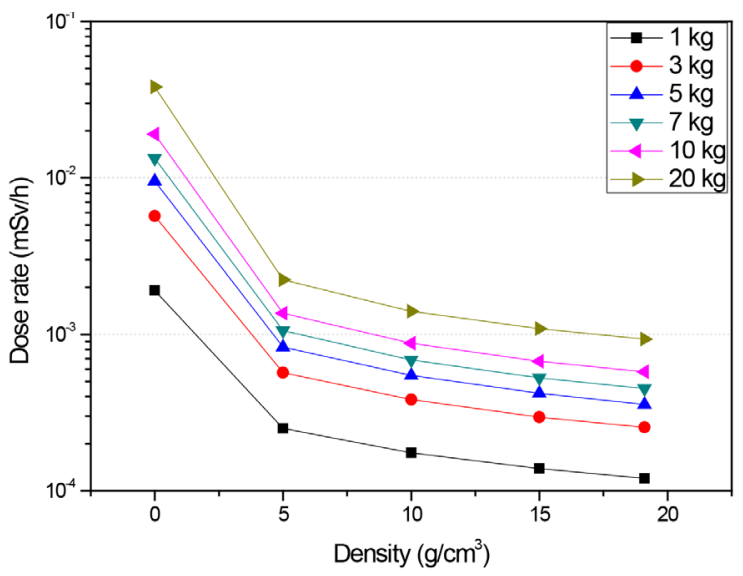

Fig. 5. Gamma dose rate with the variation of DU density.

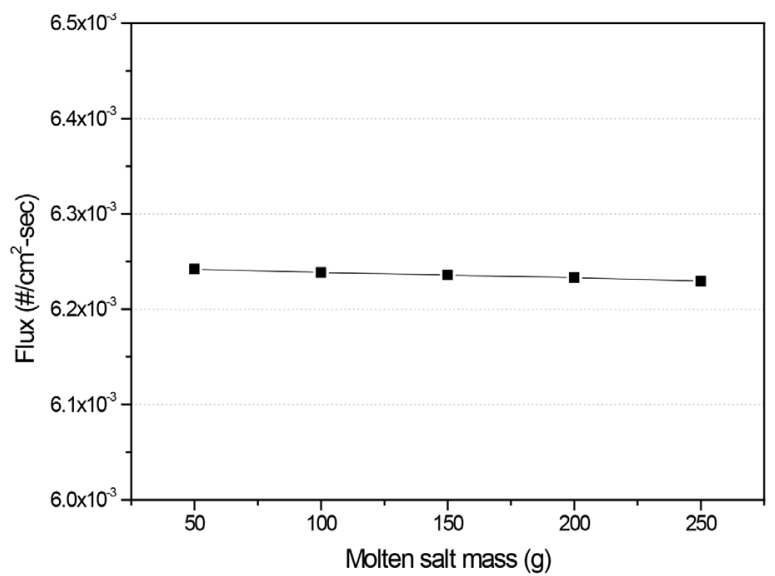

Fig. 6. Neutron flux with the variation of molten salt content.

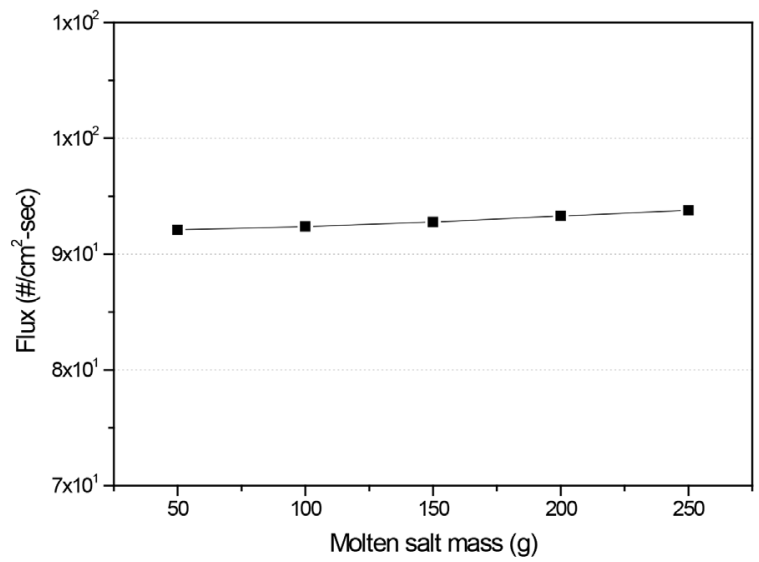

Fig. 7. Gamma flux with the variation of DU molten salt content.

\section{Flux and energy spectrum with the variation of molten salt content}

In case of DU mixed with molten salt of 50-250 g, the neutron and gamma fluxes were calculated and are shown in 


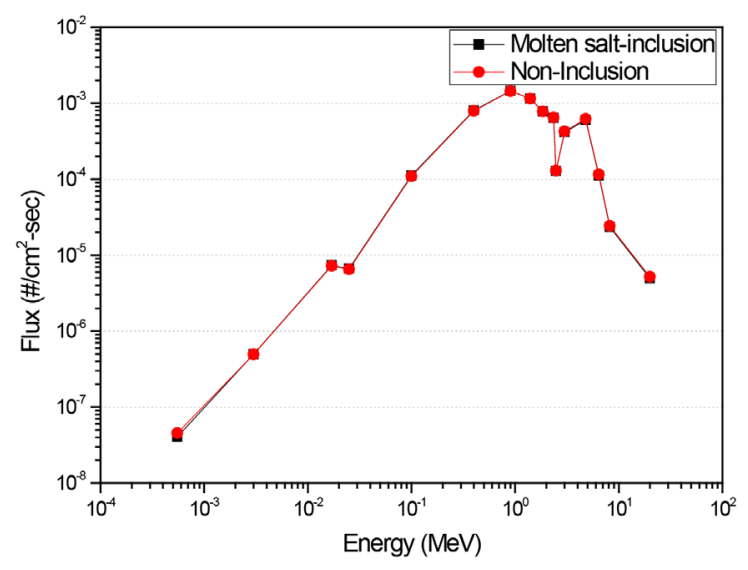

Fig. 8. Comparison of neutron energy spectra between molten salt-inclusion (50 g) and non-inclusion.

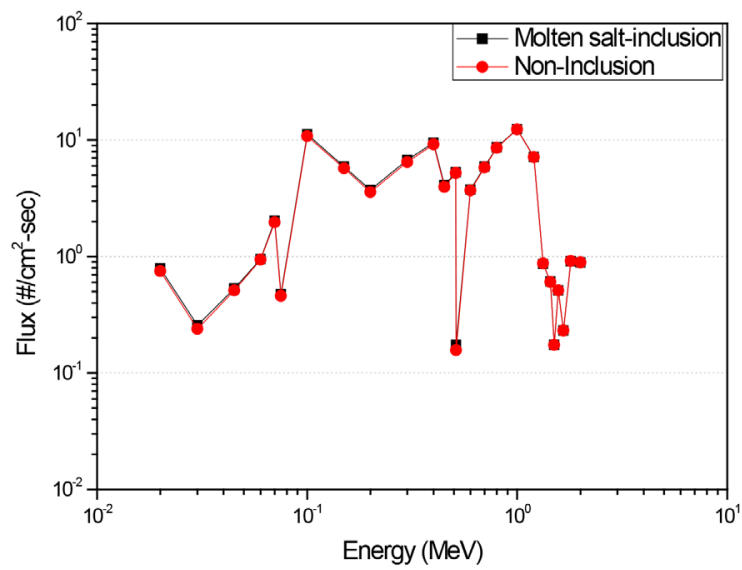

Fig. 9. Comparison of gamma energy spectra between molten salt-inclusion (50 g) and non-inclusion.

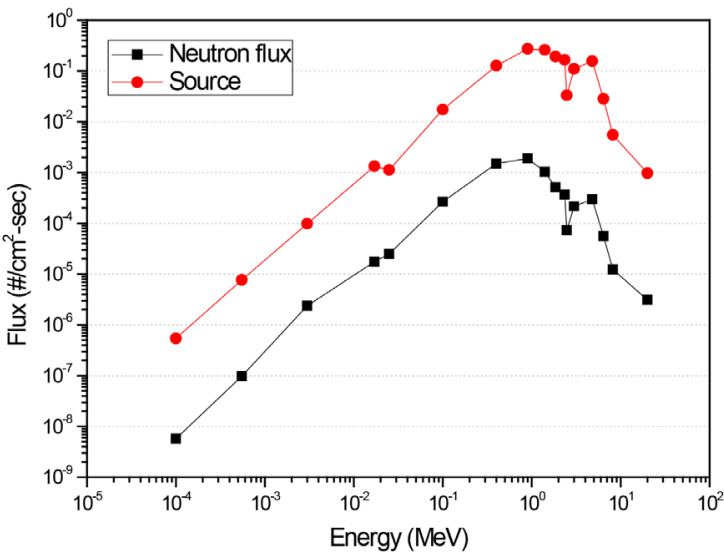

Fig. 10. Change of neutron flux by stainless steel effect. (DU: $5 \mathrm{~kg}$, density: $19.1 \mathrm{~g} \cdot \mathrm{cm}^{-3}$, stainless steel: $3 \mathrm{~mm}$, molten salt: $50 \mathrm{~g}$ ).

Figures 6 and 7, respectively. As the results of the calculation, it was found that the molten salt contents in DU had little effect on the neutron and the gamma fluxes. Also, the results of

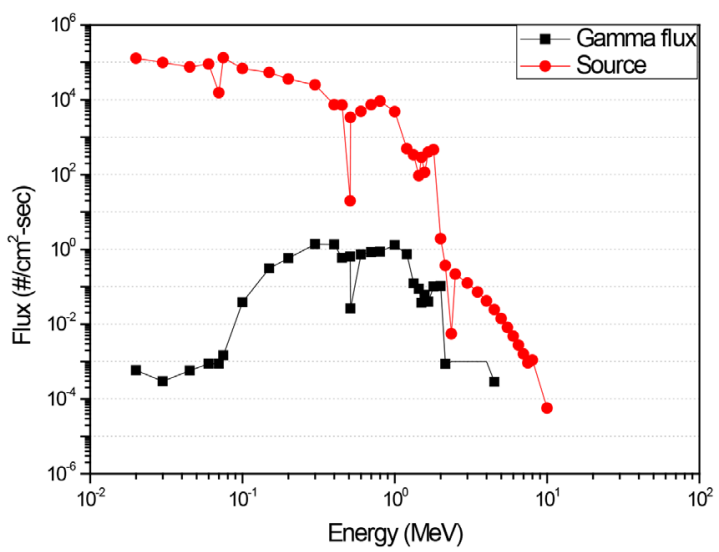

Fig. 11. Change of neutron flux by stainless steel effect. (DU: $5 \mathrm{~kg}$, density: $19.1 \mathrm{~g} \cdot \mathrm{cm}^{-3}$, stainless steel: $3 \mathrm{~mm}$, molten salt: $50 \mathrm{~g}$ ).

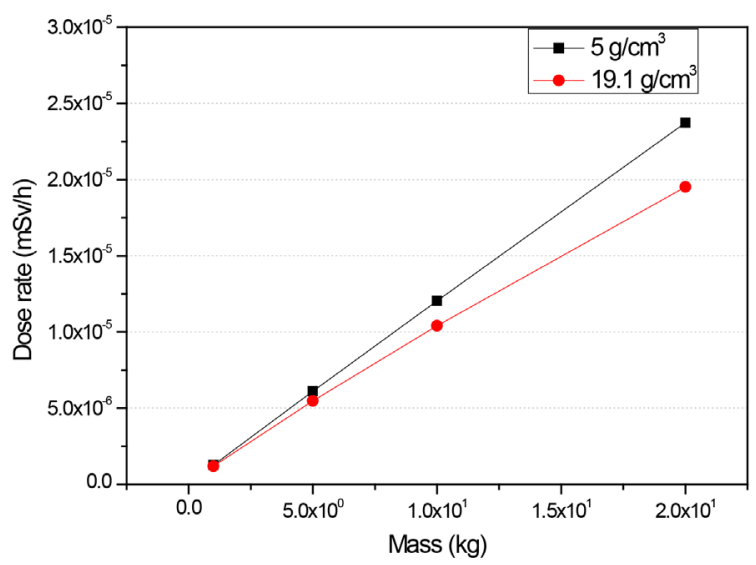

Fig. 12. Changes in neutron dose with the variation of DU mass.

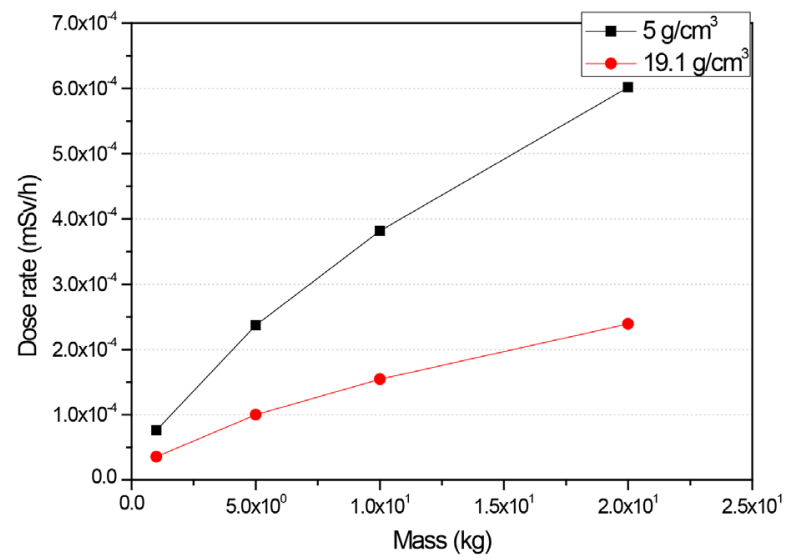

Fig. 13. Changes in gamma dose with the variation of DU mass.

the case of DU mixed with molten salt of $50 \mathrm{~g}$ was compared with those of the case containing no molten salt, and it was found that there were no differences between the spectra of 
both cases as presented in Figures 8 and 9.

\section{Flux and dose rate on the surface of SS316 container}

The neutron and the gamma fluxes, under the respective conditions of 1 and $5 \mathrm{~kg}$ mass of DU, and 5 and $19.1 \mathrm{~g} \cdot \mathrm{cm}^{-3}$ density of DU, were calculated with the molten salt $(\mathrm{LiCl}+\mathrm{KCl})$ of $50 \mathrm{~g}$ fixed, and compared with the source term. As the results, similar tendency was found in neutron and gamma fluxes with the variation of DU mass and density when compared with source spectra, except their magnitudes. In Figures 10 and 11, the calculated fluxes of neutron and gamma are shown together with source spectra, under the conditions of $5 \mathrm{~kg}$ mass and $19.1 \mathrm{~g} \cdot \mathrm{cm}^{-3}$ density of DU, with the $3 \mathrm{~mm}$ thickness of stainless steel container. And neutron and gamma dose rates were also shown in Figures 12 and 13, respectively. As seen from the figures, as the mass of DU increased from 1 to $20 \mathrm{~kg}$ and as the density of DU decreased, their dose rates were proportionally increased.

\section{Conclusions}

The neutron and gamma fluxes and dose rates were calculated for the various types of products conditions and their influences were quantitatively analyzed. With the calculation results of neutron and gamma fluxes, the neutron flux was hardly changed in spite of DU density being increased. But the gamma flux was reduced because DU took the role of self-shielding. As DU mass increased, neutron and gamma fluxes were increased proportionally. With regarding the 50$250 \mathrm{~g}$ of salt in DU mixtures, dose rates were rarely influ- enced.

As the results for the neutron and gamma dose rates outside of the $3 \mathrm{~mm}$-thick stainless steel container, it was found that the neutron dose rate from the $1 \mathrm{~kg}$ of DU was $1.26 \times 10^{-3}$ $\mu \mathrm{Sv} \cdot \mathrm{h}^{-1}$, showing very low dose rate, as expected. And the gamma dose rate for the $1 \mathrm{~kg}$ of DU was $7.61 \times 10^{-2} \mu \mathrm{Sv} \cdot \mathrm{h}^{-1}$. With considering the dose rate of environmental radiation $1.00 \times 10^{-1} \mu \mathrm{Sv} \cdot \mathrm{h}-1$ level, it is noted that the neutron and gamma doses due to DU surrounded with $3 \mathrm{~mm}$-thick stainless steel container can be regarded as lower than that of environmental radiation. In the case that density and mass of DU were $19.1 \mathrm{~g} \cdot \mathrm{cm}^{-3}$ and $5 \mathrm{~kg}$, respectively, the dose rates due to the neutron and gamma were shown to be similar with the environmental dose rate.

In the case of the DU mass over $5 \mathrm{~kg}$, the dose rate was shown to be higher than the environmental dose rate. From these results, it is concluded that if a worker would do an experiment with DU having over $5 \mathrm{~kg}$ of mass, the worker should be careful in order not to be exposed to the radiation.

\section{References}

1. Oak Ridge National Laboratory. OrigenArp Primer: How to Perform Isotropic Depletion and Decay Calculations with SCALE/ ORIGEN. ORNL/TM-2010/43. 2010;21-36.

2. Los Alamos National Laboratory. MCNP-A General Monte Carlo N-Particle Transport Code, Version 5, Volume I. LA-UR-03-1987. Chapter 2. 2003;1-139. Volume II. LA-CP-03-0245. Chapter 3. 2003;1-136. 